\title{
Solvation enthalpies of the proton in polar and non-polar solvents: Theoretical study
}

\author{
Lenka Rottmannová, Peter Škorňa, Ján Rimarčík, \\ Vladimír Lukeš, Erik Klein \\ Institute of Physical Chemistry and Chemical Physics, Slovak University of Technology in Bratislava, \\ Radlinského 9, SK-812 37 Bratislava, Slovakia \\ lenka.rottmannova@stuba.sk
}

\begin{abstract}
In spite of the importance of proton transfer in solution-phase processes, there is still no systematic theoretical study of proton solvation enthalpies. We have investigated the solvation enthalpies of the proton in seven solvents of various polarities (benzene, chloroform, acetone, methanol, ethanol, DMSO, water) using the Integral Equation Formalism Polarized Continuum Model (IEF-PCM). All computations were performed at the B3LYP and BHLYP levels of theory with aug-cc-pVDZ, aug-cc-pVTZ and aug-cc-pVQZ basis sets. Our calculations have shown that the B3LYP and BHLYP functionals provide similar solvation enthalpies. Finally, differences in the solvation enthalpy of the proton values stemming from the various basis sets do not exceed $6 \mathrm{~kJ} \mathrm{~mol}^{-1}$, with exception of DMSO and chloroform. Distance between $\mathrm{H}^{+}$and the acceptor atom of the solvent molecule is the shortest in the case of water. It has been also found that the B3LYP distances are slightly longer.
\end{abstract}

Keywords: DFT, IEF-PCM, proton solvation enthalpy, solvent

\section{Introduction}

Reactive free radicals play dominant role in deterioration of components of biosystems and synthetic organic materials via oxidative processes. Antioxidant properties of naturally occurring, as well as synthetic, antioxidants are intensively studied both, theoretically and experimentally. The majority of theoretical studies of antioxidants action thermodynamics is focused on reaction enthalpies in gas-phase. Solution-phase enthalpies, important for real systems, are still scarce. Protective role of antioxidants can be ascribed to the three mechanisms. Single-step Hydrogen Atom Transfer (HAT) mechanism is described in eq. 1

$$
\mathrm{AoH} \rightarrow \mathrm{Ao}^{\bullet}+\mathrm{H}^{\bullet}
$$

where $\mathrm{AoH}$ represents an antioxidant. This first step of free radicals scavenging is governed by dissociation enthalpy of corresponding bond. In the first step of Single Electron Transfer - Proton Transfer (SET-PT) mechanism, electron leaves the antioxidant molecule

$$
\mathrm{AoH} \rightarrow \mathrm{AoH}^{++}+\mathrm{e}^{-}
$$

Subsequently, proton is transferred and $\mathrm{Ao}^{\circ}$ is formed

$$
\mathrm{AoH}^{\cdot+} \rightarrow \mathrm{Ao}^{\bullet}+\mathrm{H}^{+}
$$

Ionization potential and proton dissociation enthalpy from $\mathrm{AoH}^{\circ+}$ radical cation describe the thermodynamics of SET-PT. Sequential ProtonLoss Electron-Transfer (SPLET), is another twostep mechanism (Musialik and Litwinienko 2005; Musialik et al. 2009)

$$
\begin{gathered}
\mathrm{AoH} \rightarrow \mathrm{Ao}^{-}+\mathrm{H}^{+} \\
\mathrm{Ao}^{-} \rightarrow \mathrm{Ao}^{\bullet}+\mathrm{e}^{-}
\end{gathered}
$$

The reaction enthalpy of the first step corresponds to the proton affinity (PA) of the $\mathrm{Ao}^{-}$anion. The reaction enthalpy of the second step, eq. 3.2, is denoted as Electron Transfer Enthalpy, ETE. It was shown that SPLET may play important role in solution phase, especially in polar solvents (Litwinienko and Ingold 2003; Staško et al. 2007; Vagánek et al. 2012). In chelating action of polyphenols, the proton loss is crucial for the protective activity of these natural antioxidants, too (Procházková et al. 2011). In general, proton transfer represents an important step in many processes in biological systems or processes of organic syntheses (Meyer et al. 2007). For complex study of reaction mechanisms in solution-phase, the knowledge of proton solvation enthalpies in various non-polar and polar solvents is essential. In spite of their importance, there is still no systematic theoretical study of proton solvation enthalpy. Therefore, main aim of this work is to compute optimal geometries for proton-solvent systems for selected non-polar and polar commonly used solvents. Computed solvation enthalpies of proton will be compared with available experimen- 
tal and/or theoretical values. For calculations, the DFT method using two functionals (B3LYP and BHLYP) has been employed. Because calculation results also depend on the basis set choice, computations have been performed for three basis sets (aug-cc-pVDZ, aug-cc-pVTZ and aug-cc-pvQZ) of different size. Chosen approach allows predicting the results for the complete basis set limit and thus to avoid errors attributed to basis set selection.

\section{Computational details}

All calculations were performed using Gaussian 03 program package (Frisch et al. 2003). The geometries of each compound or ionic structure have been optimized using density functional theory with B3LYP and BHLYP functionals without any constraints. Dunning's correlation-consistent augmented basis sets - aug-cc-pVDZ, aug-cc-pVTZ and aug-cc-pVQZ (double, triple and quadruple) were employed (Dunning 1989). From these basis sets, redundant functions have been removed and they have been rotated in order to increase the computational efficiency (Kendall et al. 1992). All basis sets were augmented with diffuse functions. The optimized structures were confirmed to be the real minima by frequency analysis.

Solvent contribution to the total enthalpies was calculated employing the Integral Equation Formalism Polarized Continuum Model, IEF-PCM, method (Cancès et al. 1997), which can be successfully applied in the description of the thermodynamic characteristics of solvation. IEF-PCM calculations were performed using default settings of Gaussian 03. We have chosen seven solvents with various polarities: benzene $\left(\mathrm{C}_{6} \mathrm{H}_{6}\right)$, chloroform $\left(\mathrm{CHCl}_{3}\right)$, acetone $\left(\mathrm{CH}_{3} \mathrm{COCH}_{3}\right)$, ethanol $\left(\mathrm{CH}_{3} \mathrm{CH}_{2} \mathrm{OH}\right)$, methanol $\left(\mathrm{CH}_{3} \mathrm{OH}\right)$, dimethylsulfoxide (DMSO, $\left.\left(\mathrm{CH}_{3}\right)_{2} \mathrm{SO}\right)$ and water.

The total enthalpies of the species $\mathrm{X}, H(\mathrm{X})$, at the temperature $T$ are estimated from the expression
$H(\mathrm{X})=E_{0} \mathrm{ZPE}+\Delta H_{\mathrm{trans}}+\Delta H_{\mathrm{rot}}+\Delta H_{\mathrm{vib}}+R T$

where $E_{0}$ is the total electronic energy, ZPE stands for zero-point energy, $\Delta H_{\text {trans }}, \Delta H_{\text {rot }}$ and $\Delta H_{\text {vib }}$ are the translational, rotational and vibrational contributions to the enthalpy. Finally, $R T$ represents PV-work term and is added to convert the energy to enthalpy (Atkins 1998). All enthalpies were calculated for $298.15 \mathrm{~K}$.

\section{Results and discussion}

The calculated gas-phase enthalpy of proton, $H\left(\mathrm{H}^{+}\right)$, is taken as that for an ideal gas $5 / 2 R T$ or $6.197 \mathrm{~kJ} \mathrm{~mol}^{-1}$ (Bartmess 1994). The $\mathrm{H}^{+}$solvation enthalpies in organic solvents determined using IEF-PCM DFT calculations are summarized in Table 1. Data in this table have been obtained as the enthalpy change related to this process

$$
\text { solvent }(\mathrm{l})+\mathrm{H}^{+}(\mathrm{g}) \rightarrow[\text { solvent }-\mathrm{H}]^{+}(\text {solv })
$$

where proton was "attached" to one molecule of solvent placed in the cavity of the same solvent. Studied systems are depicted in Fig. 1. The only available experimental value of proton solvation enthalpy is its hydration enthalpy, $\Delta_{\text {hydr }} H\left(\mathrm{H}^{+}\right)=-1090 \mathrm{~kJ} \mathrm{~mol}^{-1}$ (Atkins 1998). Several B3LYP/6-311++G** solvation enthalpies were published in (Rimarčík et al. 2010). Fifen et al. (2011) obtained practically identical values. For proton hydration enthalpy, Mejías and Lago (2000) performed calculations including explicit water molecules solvating $\mathrm{H}^{+}$. They found a value of $-999 \mathrm{~kJ} \mathrm{~mol}^{-1}$. This indicates that IEF-PCM method is able to provide reliable results with one explicit solvent molecule consideration. Another theoretical study investigated the thermochemistry of the proton solvation in methanol within the cluster-continuum model. Used calculation scheme involves up to nine explicit methanol molecules using the IEF-PCM at B3LYP/6-31++G** $\left(\Delta_{\text {solv }} H\left(\mathrm{H}^{+}\right)=-1084 \mathrm{~kJ} \mathrm{~mol}{ }^{-1}\right)$ and M062X/6-31-

Tab. 1. B3LYP and BHLYP (in parenthesis) solvation enthalpies of proton, $\Delta_{\text {solv }} H\left(\mathrm{H}^{+}\right)$, in studied solvents in $\mathrm{kJ} \mathrm{mol}^{-1}$ and relative permitivities $\varepsilon_{\mathrm{r}}$

\begin{tabular}{lcccc}
\hline solvent & $\varepsilon_{\mathbf{r}}{ }^{\mathbf{a}}$ & aug-cc-pVDZ & aug-cc-pVTZ & aug-cc-pVQZ \\
\hline benzene & 2.271 & $-885(-885)$ & $-885(-885)$ & $-886(-885)$ \\
chloroform & 4.711 & $-863(-850)$ & $-877(-863)$ & $-878(-865)$ \\
acetone & 20.493 & $-1047(-1051)$ & $-1050(-1054)$ & $-1051(-1055)$ \\
ethanol & 24.852 & $-1043(-1047)$ & $-1047(-1052)$ & $-1048(-1052)$ \\
methanol & 32.613 & $-1034(-1038)$ & $-1038(-1043)$ & $-1039(-1044)$ \\
DMSO & 46.826 & $-1119(-1127)$ & $-1112(-1120)$ & $-1110(-1117)$ \\
water & 78.355 & $-1016(-1020)$ & $-1021(-1025)$ & $-1022(-1026)$ \\
\hline
\end{tabular}

${ }^{\mathrm{a}}$ From the Ref. (Wilhelm and Battino 1973), and references therein. 
$++\mathrm{G}^{* *}\left(\Delta_{\text {solv }} H\left(\mathrm{H}^{+}\right)=-1054 \mathrm{~kJ} \mathrm{~mol}^{-1}\right)$ levels of theory (Fifen et al. 2013).

For the majority of studied solvents, differences in proton solvation enthalpies related to B3LYP and BHLYP functionals are within $5 \mathrm{~kJ} \mathrm{~mol}^{-1}$. Larger difference have been found only for chloroform $\left(14 \mathrm{~kJ} \mathrm{~mol}^{-1}\right)$ and DMSO $\left(8 \mathrm{~kJ} \mathrm{~mol}^{-1}\right)$. Differences in proton solvation enthalpies resulting from the various basis sets do not exceed $6 \mathrm{~kJ} \mathrm{~mol}^{-1}$, with exception of $\mathrm{CHCl}_{3}$ and DMSO. For these two solvents containing heavier chlorine or sulfur atoms, they reached 10 and $15 \mathrm{~kJ} \mathrm{~mol}^{-1}$, respectively. Differences in proton solvation enthalpies obtained using triple zeta (aug-cc-pVTZ) and computationally more demanding quadruple zeta (aug-cc-pVQZ) basis set calculations can be considered negligible. Therefore, one could presume that results for quadruple zeta basis set are close to the infinite basis set limit and they may be employed in the evaluation of reaction enthalpies for processes including proton transfer in solution-phase. In comparison to quadruple zeta (aug-cc-pVQZ) basis set, already the smallest used double zeta (aug-cc-pVDZ) basis set (see Table 1) gives proton solvation enthalpies higher only by few units of $\mathrm{kJ} \mathrm{mol}^{-1}$ and may be considered sufficient as the rational compromise between the accuracy of results and computational costs. For both functionals, the influence of the basis set size is identical and can be considered negligible.

Obtained results are in good agreement with 6 available IEF-PCM-B3LYP/6-311++G** proton solvation enthalpies published in (Rimarčík et al. 2010). Differences for IEF-PCM-B3LYP/aug-cc-pVQZ do not exceed $19 \mathrm{~kJ} \mathrm{~mol}^{-1}$. The largest difference was

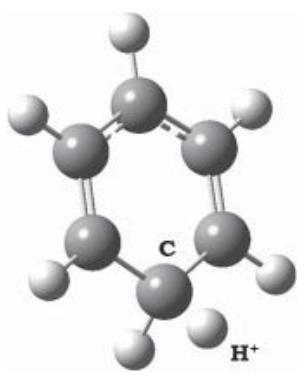

(a)

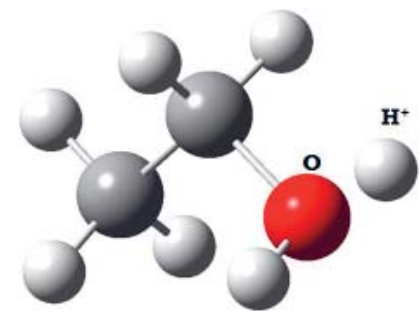

(d)

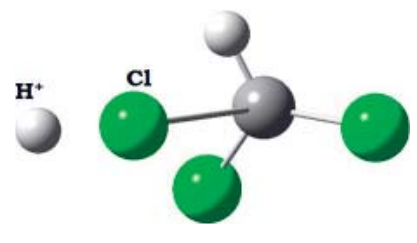

(b)

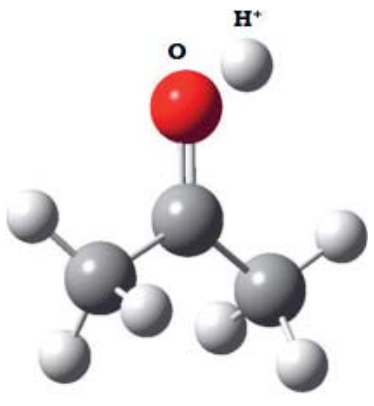

(c)

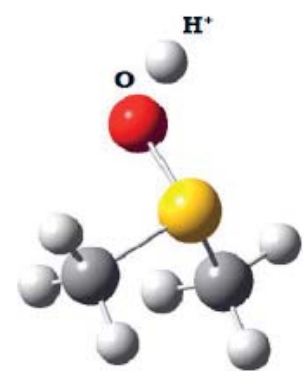

(f)

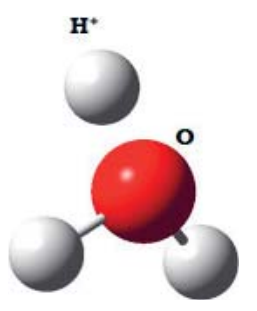

(g)

Fig. 1. Studied $[\text { solvent }-\mathrm{H}]^{+}$species. Solvents: benzene (a), chloroform (b), acetone (c), ethanol (d), methanol (e), DMSO (f), water (g).

Tab. 2. Optimal B3LYP and BHLYP (in parenthesis) distances between $\mathrm{H}^{+}$and the acceptor atom of solvent in $\AA$.

\begin{tabular}{lcccc}
\hline solvent & acceptor atom* & aug-cc-pVDZ & aug-cc-pVTZ & aug-cc-pVQZ \\
\hline benzene & $\mathrm{C}$ & $1.114(1.104)$ & $1.107(1.098)$ & $1.107(1.098)$ \\
chloroform & $\mathrm{Cl}$ & $1.323(1.309)$ & $1.309(1.296)$ & $1.308(1.295)$ \\
acetone & $\mathrm{O}$ & $1.009(0.993)$ & $1.006(0.991)$ & $1.004(0.989)$ \\
ethanol & $\mathrm{O}$ & $0.999(0.986)$ & $0.997(0.983)$ & $0.995(0.982)$ \\
methanol & $\mathrm{O}$ & $1.001(0.987)$ & $0.998(0.984)$ & $0.997(0.983)$ \\
DMSO & $\mathrm{O}$ & $1.004(0.989)$ & $1.001(0.986)$ & $1.000(0.985)$ \\
water & $\mathrm{O}$ & $0.998(0.985)$ & $0.995(0.983)$ & $0.994(0.982)$ \\
\hline
\end{tabular}

*See Fig. 1. 
found for acetone. For the rest of solvents, calculated and published proton solvation enthalpies are within $8 \mathrm{~kJ} \mathrm{~mol}^{-1}$.

Optimum geometries of studied [solvent $-\mathrm{H}]^{+}$species depend on both, functional selection and the basis sets quality. Distances between proton and acceptor atom of solvent molecule (Fig. 1) are compiled in Table 2. The larger the basis set, the shorter the $\mathrm{H}^{+}$-solvent distance. For solvents with oxygen as acceptor atom, these distances are about $1.0 \AA$. For carbon atom in benzene and chlorine atom in $\mathrm{CHCl}_{3}$ they reached ca 1.1 and $1.3 \AA$, respectively. Distance between $\mathrm{H}^{+}$and the acceptor oxygen atom of the solvent molecule is the shortest in the case of water. If one compares results provided by the two functionals, values in Table 2 show that B3LYP distances are slightly longer.

\section{Conclusion}

In this work, we present quantum chemical calculations of proton solvation enthalpies for commonly used solvents of various polarities applying IEFPCM DFT approach. B3LYP and BHLYP functionals provide similar results. Differences in proton solvation enthalpies resulting from the aug-ccpVDZ, aug-cc-pVTZ and aug-cc-pVQZ basis sets do not exceed $6 \mathrm{~kJ} \mathrm{~mol}^{-1}$, with exception of $\mathrm{CHCl}_{3}$ and DMSO. Obtained proton solvation enthalpies are in accordance with previously published data. Calculated proton solvation enthalpies, $\Delta_{\text {solv }} H\left(\mathrm{H}^{+}\right)$, can be utilized in evaluation of reaction enthalpies of various proton transfer processes in solution-phase.

\section{Acknowledgement}

This work was supported by courtesy of the Slovak Grant Agency (VEGA 1/0735/13) and J.R. thanks to SUT young researcher grant.

\section{References}

Atkins PW (1998) Physical chemistry, $6^{\text {th }}$ ed., Oxford University Press, Oxford.
Bartmess JE (1994) J. Phys. Chem. 98: 6420-6424.

Cancès E, Mennucci B, Tomasi J (1997) J. Chem. Phys. 107: 3032-3041.

Dunning TH Jr. (1989) J. Chem. Phys. 90: 1007-1023.

Fifen JJ, Nsangou M, Dhaouadi Z, Motapon O, Jaidane N (2011) Comp. Theor. Chem. 966: 232-243.

Fifen JJ, Nsangou M, Dhaouadi Z, Motapon O, Jaidane N (2013) J. Chem. Theory Comput. 9: 1173-1181.

Frisch MJ, Trucks GW, Schlegel HB Scuseria GE, Robb MA, Cheeseman JR, Montgomery JA, Jr., Vreven T, Kudin KN, Burant JC, Millam JM, Iyengar SS, Tomasi J, Barone V, Mennucci B, Cosi M, Scalmani G, Rega N, Petersson GA, Nakatsuji H, Hada M, Ehara M, Toyota K, Fukuda R, Hasegava J, Ishida M, Nakajima T, Honda Y, Kitao O, Nakai H, Klene M, Li X, Knox JE, Hratchian HP, Cross JB, Adamo C, Jaramillo J, Gomperts R, Stratmann RE, Yazyev O, Austin AJ, Cammi R, Pomelli C, Ochterski JW, Ayala PY, Morokuma K, Voth GA, Salvador P, Dannenberg JJ, Zakrzewski VG, Dapprich S, Daniels AD, Strain M-C, Farkas O, Malick DK, Rabuck AD, Raghavachari K, Foresman JB, Ortiz JV, Cui Q, Baboul AG, Clifford S, Cioslowski J, Stefanov BB, Liu G, Liashenko A, Piskorz P, Komaromi I, Martin RL, Fox DJ, Keith T, Al-Laham MA, Peng CY, Nakaryakkara A, Chalacombe M, Gill PMW, Johnson B, Chen W, Wong MW, Gonzales C, Pople JA (2003) GAUSSIAN 03, Revision A.1, Gaussian, Inc., Pittsburgh, PA.

Kendall RA, Dunning TH, Harrison RJ (1992) J. Chem. Phys. 96: 6796-6806.

Litwinienko G, Ingold KU (2003) J. Org. Chem. 68: 3433-3438.

Mejías JA, Lago S (2000) J. Chem. Phys. 113: 73067316.

Meyer TJ, Huynh MHV, Thorp HH (2007) Angew. Chem. Int. Ed. 46: 5284-5304.

Musialik M, Kuzmicz R, Pawlowski TS, Litwinienko G (2009) J. Org. Chem. 74: 2699-2709.

Musialik M, Litwinienko G (2005) Org. Lett. 7: 49514954.

Procházková D, Boušová I, Wilhelmová N (2011) Fitoterapia 82: 513-523.

Rimarčík J, Lukeš V, Klein E, Ilčin M (2010) J. Mol. Struc. 952: 25-30.

Staško A, Brezová V, Biskupič S, Mišík V (2007) Free Radical Res. 41: 379-390.

Vagánek A, Rimarčík J, Lukeš V, Klein E (2012) Comp. Theor. Chem. 991: 192-200.

Wilhelm E, Battino R (1973) Chem. Rew. 73: 1-9. 